\title{
Rancang Bangun Pengendali Pompa Miniatur Berbasis Mikrokontroler Arduino Bluetooth $4 \mathrm{Ch}$
}

\author{
Arief Muliawan', Finta Amalinda ${ }^{2}$, Irvan Prasetio ${ }^{3}$ \\ ${ }^{1}$ Sekolah Tinggi Teknologi Bontang, Jln. Ir. H. Juanda No.73 Bontang \\ ${ }^{2}$ Universitas Muhammadiah Palu, Jln. Hang Tuah No.114 Palu \\ ${ }^{3}$ SMA Bahrul Ulum Bontang \\ Korespondensi: ariefstitek@gmail.com
}

\begin{abstract}
Abstrak: Pompa air yang sering kita miliki memegang peranan penting dalam pendistribusian pada instalasi air di rumah. Pengoperasian ini terkadang membutuhkan waktu yang lama sehingga membutuhkan sistem kontrol yang efesien. Aplikasi smartphone pada android dapat dipadukan dengan mikrokontroler seperti pada aplikasi mikrokontroler arduino uno. Pemanfaatan aplikasi android dan mikrokontroler ini dapat dipergunakan pada kontrol pompa air. Dalam peneltian ini dimaksudakan untuk mengkoneksikan arduino uno dengan pompa yang terintegrasi dengan bluethooth. Bluethooth yang dipergunakan dengan seri HC-5 yang dapat dikoneksikan dengan sinyal yang dimiliki oleh aplikasi android yang berada di smartphone dengan seri arduino uno bluethoot $4 \mathrm{CH}$. Kinerja alat ditampilkan dalam tampilan LCD 4x16 yang menyatakan waktu pemakaian dan on-off pemakaian pompa. Dari hasil pengujian kemampuan pompa beroperasi selama 1 menit diperoleh hasil perhitungan dengan debit $38.23 \mathrm{~cm}^{3} / \mathrm{s}$ dengan kecepatan aliran $28.8 \mathrm{~cm} / \mathrm{s}$.
\end{abstract}

Kata kunci : Mikrokotroler, pengendali pompa, bluetooth $4 \mathrm{Ch}$.

\begin{abstract}
The water pump we often have plays an important role in the distribution of home water installations. This operation sometimes takes a long time and thus requires an efficient control system. Smartphone application on android can be integrated with microcontroller as arduino uno microcontroller application. Utilization of android application and this microcontroller can be used in water pump control. In this study it is intended to connect arduino uno with pumps integrated with bluethooth. Bluethooth is used with the HC-5 series that can be connected with signals owned by android applications that are in the smartphone with the series arduino uno bluethoot 4Ch. Performance of the tool is displayed in 4x16 LCD display which states the time of discharging and on-off the pump. From the results of testing the ability of the pump to operate for 1 minute obtained the calculation results with the discharge $28.23 \mathrm{~cm}^{3} / \mathrm{s}$ with flow rate $28.8 \mathrm{~cm} / \mathrm{s}$.
\end{abstract}

Keywords: microcontroller, pump controller, bluetooth 4 Ch.

\section{PENDAHULUAN}

Pompa air yang sering kita miliki memegang peranan penting dalam pendistribusian pada instalasi air di rumah terutama penyaluran dari pipa PDAM ke bak penampungan. Pengoperasian ini terkadang membutuhkan waktu yang lama dalam pengorasian sehingga membutuhkan sistem kontrol yang efesien [1]. Peranan teknologi elektronika mempengaruhi kinerja sistem kontrol yang semakin cangih dan muktahir.

Tekanan air menjadi salah satu parameter penting yang selalu menjadi perhatian penggunanya. Ada beberapa sistem yang kerjanya dipengaruhi oleh tekanan air seperti pemanas air rumah tangga. Jika tekanan air yang masuk ke pemanas air berubah-ubah, maka suhu air menjadi tidak stabil. Tekanan air harus dipertahankan konstan agar hal tersebut tidak terjadi [2]. Dengan mengunakan tekanan yang baik terhadap aliran air maka dapat dibuat filter air sehingga keluaran air menjadi lebih bersih $[3,4]$. Dalam pengunaan pompa diperlukan alat yang mampu memberikan tekanan dan bersifat otomatis jika dikendalikan jarak jauh. Dalam pengendali jarak jauh dengan jarak yang tidak begitu jauh salah satu solusi yakni dengan menggunakan bluetooth. Perkembangan teknologi dapat terlihat pada perkembangan smartphone dengan memanfaatkan teknologi bluetooth [5]. 
Smarthpone yang berkembang sangat pesat ini menimbulkan kreatifitas dalam pembuatan aplikasi yang semakin berfariasi. Aplikasi smartphone dapat dipadukan dengan aplikasi mikrokontroler seperti pada aplikasi mikrokontroler arduino uno [6]. Aplikasi bluetooth yang di smartphone dapat dipadukan dengan aplikasi arduino uno seperti pada aplikasi arduino bluetooth 4 chanel yang mana aplikasi ini sangat bermanfaat mengendalikan perintah yang diaplikasikan ke dalam mikrokontroler arduino uno. Pemanfaatan aplikasi dan mikrokontroler ini dapat dipergunakan pada kontrol pompa air.

Alat yang dibuat pada penelitian ini adalah automatic pump with smartpone (pompa otomatis dengan smartpone). Alat ini dibuat untuk mengontol pompa air (on-off) tanpa menggunakan saklar, tetapi bekerja secara otomatis menggunakan teknologi smartpone dengan koneksi bluetooth. Hasil dari pembuatan alat ini untuk mempermudah pekerjaan manusia karena dengan menggunakan smartpone untuk mengendalikan pompa air tanpa harus menggunakan saklar, yang dimana kerugian saklar yaitu sering terjadi konslet ataupun terbakar, serta menambah kreatifitas dibidang elektronika.

\section{METODE DAN BAHAN}

\section{Alat dan Bahan}

Pada penelitian ini, alat pompa miniatur berbasis mikrokontroler arduino bluethoot mengunakan spesifikasi perangkat keras (hardware) dan perangkat lunak (software) yang dibutuhkan dalam pembuatan alat ini dapat dilihat pada tabel 1.

Tabel 1. Kebutuhan Perangkat Keras

\begin{tabular}{|c|l|l|}
\hline No & Nama Perangkat & \multicolumn{1}{c|}{ Spesifikasi } \\
\hline 1 & Laptop & OS windows 7 32 BIT, Intel(R) atom (TM) CPU N2800, Ram 2Gb \\
\hline 2 & Mikrokontroller & Arduino Uno, Atmega 328 \\
\hline 4 & Power Supply & 12 volt, 2 Ampere \\
\hline 5 & Grove Relay & 5 Volt 10 Ampere \\
\hline 6 & Konverter & 5 volt, dan 9 volt \\
\hline 7 & Saklar & On-off \\
\hline 8 & bluethoot & HC-05 \\
\hline 9 & RTC & Ds3231 \\
\hline 10 & LCD & $16 \times 4$ \\
\hline 11 & Pompa Air & SP-1000, 220 VAC \\
\hline 12 & Fan & 12 volt dc \\
\hline 13 & Akuarium akrilik & $398 \times 254$ x 372 mm \\
\hline
\end{tabular}

Sedangkan untuk kebutuhan perangkat lunak (software) seperti pada tabel 2.

Tabel 2. Kebutuhan Perangkat Lunak

\begin{tabular}{|c|c|c|}
\hline No & Nama Perangkat & Spesifikasi \\
\hline 1 & Arduino IDE & Bahasa C \\
\hline 2 & Software Rangkaian & Fritzing, Proteus 7 \\
\hline 3 & Software smartphone & Arduino Bluethoot CH4 \\
\hline
\end{tabular}

Pembuatan Prototipe ini juga memakai beberapa perlengkapan alat, adapun alat yang digunakan dapat dilihat pada tabel 3.

Tabel 3. Kebutuhan Alat

\begin{tabular}{|c|l|l|}
\hline No & \multicolumn{1}{|c|}{ Nama Alat } & \multicolumn{1}{c|}{ Spesifikasi } \\
\hline 1 & Tool set & \\
\hline 2 & AVO meter & AC,DC \\
\hline 3 & Solder Timah & 220VAC \\
\hline 4 & Penyedot Timah & Vacum \\
\hline
\end{tabular}

\section{Perancangan Alat}

Perancangan dilakukan bertahap untuk memudahkan analisa sistem setiap bagian maupun sistem secara keseluruhan. Perancangan dan pembuatan sistem ini terdiri dari dua perancangan utama, yaitu perancangan perangkat keras dan perancangan perangkat lunak (software). Perancangan perangkat keras meliputi perancangan rangkaian input, 
perancangan rangkaian output dan perancangan rangkaian kontrol. Perancangan perangkat lunak (software) meliputi perancangan skematik alat dan perancangan proses flowchart yang akan menjelaskan sistem kerja alat secara menyeluruh.

Pada alat otomatis berbasis Arduino Uno ini rangkaian terdiri dari beberapa bagian, yaitu,Arduino Uno, LCD, relay, bloototh. Arduino akan aktif apabila dipicu oleh arus kecil dari mikrokontroller. Untuk menampilkan data digunakan LCD 16x4, LCD 16x4 disini memiliki 16 buah pin. Untuk mengurangi jumlah pemakaian pin maka dipasang modul I2C sehingga hanya memakai 4 pin.

Power supply yang digunakan mempunyai tegangan 12volt dan akan diturunkan menjadi 5 volt untuk RTC, Bluetooth dan relay, serta 9volt untuk arduino uno. Pemasangan power supply dapat dilihat pada gambar 1 .

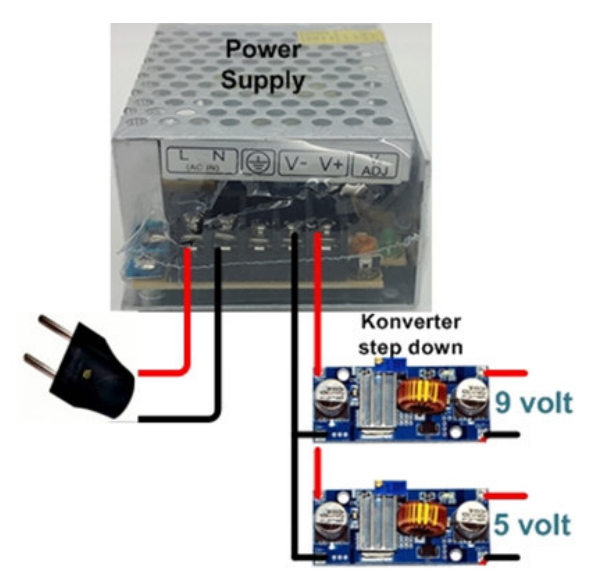

Gambar 1. Pemasangan Power supply

Tegangan DC output yang terdapat dipower supply sebesar 12volt yang ditandai dengan $\mathrm{V}-, \mathrm{V}+$ dihubungkan ke masukan dari konverter. Untuk menentukan tegangan yang diinginkan putar trimpot yang berada dikonverter agar sesuai dengan output tegangan yang diinginkan.

Pemasangan Konverter dilakukan pada penelitian ini mengunakan dua konverter stepdown yakni konverter 9VDC dan 5 VDC. Sumber tegangan yang berasal dari power suplay yang diberiken tegangan output 12 VDC harus di turunkan dan distabilkan ke 9VDC dan 5VDC. Pemakaian tegangan 9VDC pada arduino uno sedangkan pemakaian 5VDC pada relay.

LCD yang dipakai pada penelitian ini menggunakan LCD16x 4 yaitu LCD dengan jumlah kolam sebanyak 16 kolom dan 4 barisyang mempunyai 16 pin, fungsi dari pin-pin tersebut yaitu: Vss, Vdd, Vo,RS, RW, E, D0, D1, D2, D3, D4, D5, D6, D7, A, dan K [7].LCD ini akan digunakan sebagai penampil nilai waktu dan proses alat berlangsung. Untuk menghemat penggunaan pin pada LCD digunakan I2C, apabila tidak menggunakan I2C maka harus menggunakan 5 pin digital. Ketika menggunakan I2C hanya menggunakan pin sda dan scl. LCD 16X4 digunakan sebagai penampi linformasi proses yang sedang berjalan seperti nilai sensor dan keterangan aktuator. Pengaplikasian I2C dengan LCD16X4 seperti gambar dibawah ini.

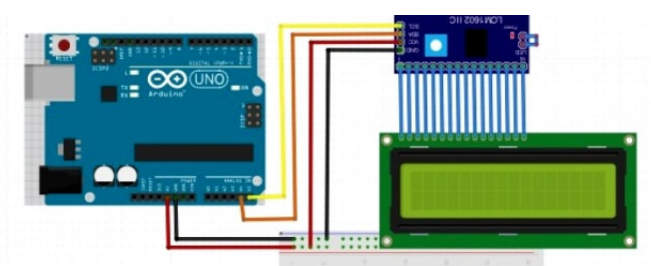

Gambar 2. Rangkaian LCD 16 X 4

Modul bluetooth HC-05 merupakan module komunikasi nirkabel pada frekuensi $2.4 \mathrm{GHz}$ dengan pilihan koneksi bisa sebagai slave, ataupun sebagai master. Sangat mudah 
digunakan dengan mikrokontroler untuk membuat aplikasi wireless. Interface yang digunakan adalah serial RXD, TXD, VCC dan GND. Built in LED sebagai indikator koneksi bluetooth. Tegangan input antara $3.6 \sim 6 \mathrm{~V}$, jangan menghubungkan dengan sumber daya lebih dari $7 \mathrm{~V}$. Arus saat unpaired sekitar $30 \mathrm{~mA}$, dan saat paired (terhubung) sebesar $10 \mathrm{~mA}$. Selanjutnya penambahan relay pada rangkaian. Relay merupakan saklar (Switch) yang dioperasikan secara listrik dan merupakan komponen Electromechanical (Elektromekanikal) yang terdiri dari 2 bagian utama yakni Elektromagnet (Coil) dan Mekanikal (seperangkat kontak saklar/switch). Relay menggunakan prinsip Elektromagnetik untuk menggerakkan Kontak Saklar sehingga dengan arus listrik yang kecil (low power) dapat menghantarkan listrik yang bertegangan lebih tinggi. Pada pemasangan keseluruhan sistem dihubungkan ke berbagai rangkaian. Dapat dilihat pada gambar 3.

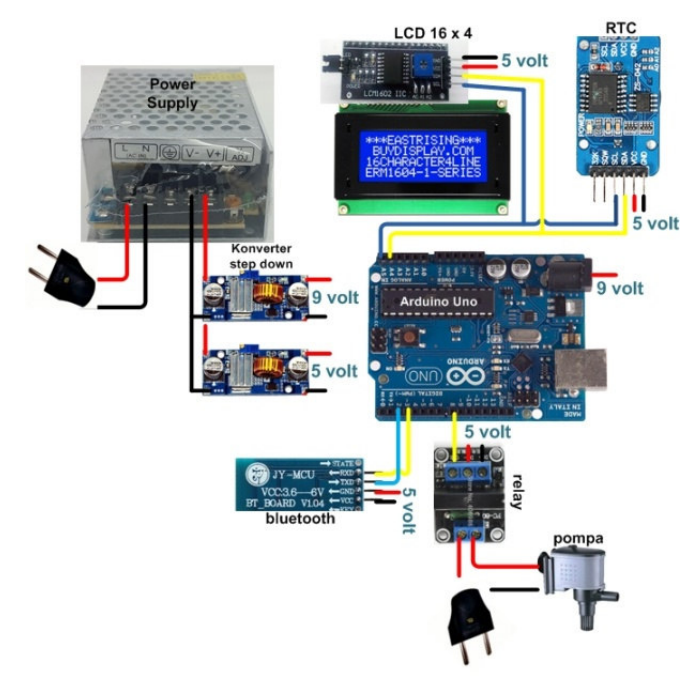

Gambar 3. Pemasangan keseluruhan sistem

Aplikasi yang digunakan dalam penelitian ini yaitu Arduino Bluetooth 4Ch. Aplikasi ini digunakan untuk mengkoneksikan arduino dengan smartpone dengan bantuan koneksi bluetooth. Aplikasi ini dapat di download pada android smartphone melaui playstore.

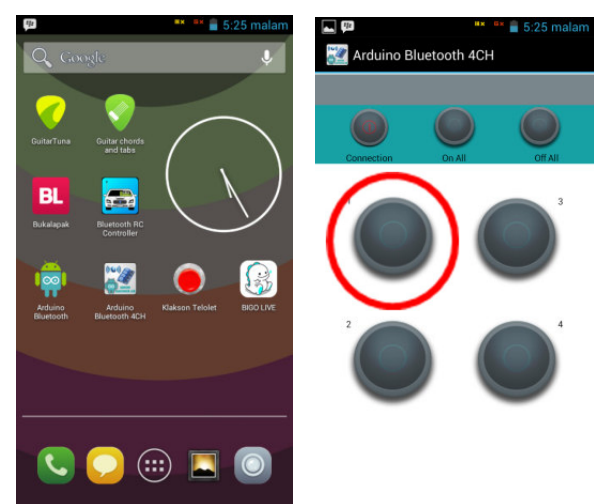

Gambar 4. Tampilan Arduino bluetooth 4CH

\section{HASIL DAN PEMBAHASAN}

Pada Arduino uno terdapat pin yang dihubungkan ke rangkaian lainnya, pada pin analog A4, A5 Arduino uno dihungkan ke pin SDA, SDL milik LCD dan RTC. Dibagian Pin digital8 Arduino uno dihubungkan kepin $\mathrm{CH} 1$ milik relay. Serta pin digital 2, 3 Arduino 
uno dihubungkan ke pin TX, RX milik bluetooth. Hasil perancangan alat ditunjukan pada gambar 5.

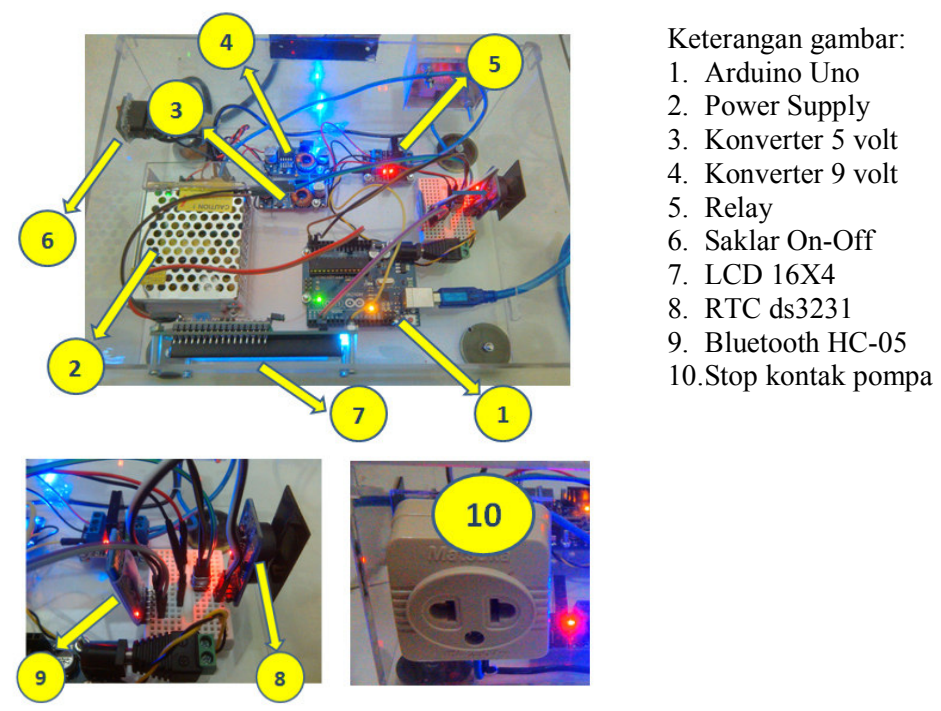

Gambar 5. Tampilan Keseluruhan Alat

Kemudian dilakukan pengambilan data terhadap kinerja pompa. Setelah dilakukan pengamatan dan pengambilan data penelitian diperoleh hasil seperti pada tabel 4 .

Tabel 4. Pengambilan Data Penelitian

\begin{tabular}{|c|c|c|c|c|}
\hline \multirow{2}{*}{ No } & Diameter & Waktu & Kedalaman & Volume \\
\cline { 2 - 5 } & Pipa $(\mathrm{cm})$ & $(\mathrm{s})$ & $(\mathrm{cm})$ & $(\mathrm{dm} 3)$ \\
\hline 1 & 1.3 & 60 & 5 & 2.23 \\
\hline 2 & 1.3 & 60 & 10 & 2.27 \\
\hline 3 & 1.3 & 60 & 15 & 2.31 \\
\hline 4 & 1.3 & 60 & 20 & 2.32 \\
\hline 5 & 1.3 & 60 & 25 & 2.34 \\
\hline
\end{tabular}

Dengan melakukan pengukuran terhadap pipa penyedot sebesar $1.3 \mathrm{~cm}$ maka luas penampang dari pipa dapat diperoleh $A=\frac{1}{4} \pi d^{2}=\frac{1}{4} \cdot 3.14 \cdot(1.3)^{2}=1.33 \mathrm{~cm}^{2}$

Selanjutnya dapat kita hitung volume yang dikonversi ke $\mathrm{cm}$ sebagai berikut: $V=2.23 \mathrm{dm}^{3}=2230 \mathrm{~cm}^{3}$

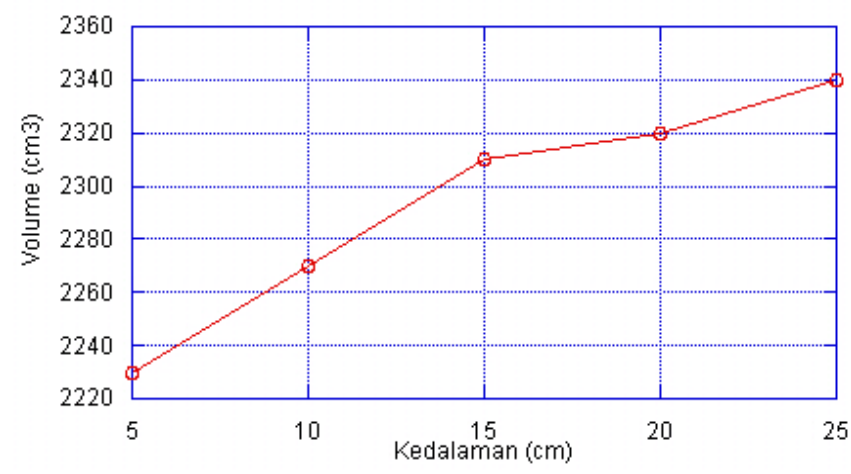

Gambar 6. Grafik perubahan volume keluaran terhadap kedalaman

Dari pengukuran yang dilakukan terhadap jumlah keluaran volume terhadap kedalaman terlihat peningkatan sesuai dengan kedalaman. Sehingga jika dirata-ratakan maka jumlah volume yang keluar berdasarkan pengukuran ini diperoleh $2294 \mathrm{~cm}^{3}$. Dari perhitungan 
yang dilakukan terhadap jumlah volume air yang diperoleh selama 1 menit (60 detik) dengan ini dapat ditunjukan grafik pada gambar 7 .

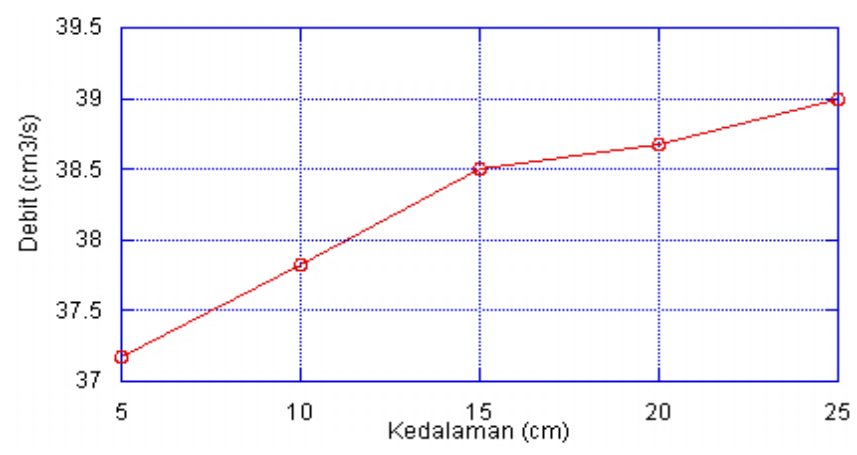

Gambar 7. Grafik perubahan debit keluaran terhadap kedalaman

Dari grafik debit yang ditunjukan pada gambar 7 diperoleh gambaran bahwa debit keluaran hampir konstan terhadap pengukuran kedalaman. Dengan melakukan perhitungan rerata diperoleh $38.23 \mathrm{~cm}^{3} / \mathrm{s}$. Selanjutnya dilakukan perhitungan laju aliran

Dengan menghitung kecepatan aliranuntuk tiap kedalaman dapat dilihat pada tabel 5 . Perhitungan rerata dari keadaan pompa dapat dilakukan dengan kondisi kecepatan aliran $28.8 \mathrm{~cm} / \mathrm{s}$. Hasil perhitungan lengkap ditunjukan pada tabel 5 .

Tabel 5. Hasil perihtungan kinerja pompa

\begin{tabular}{|c|c|c|c|c|c|}
\hline \multirow{2}{*}{ No } & dalam & Luas & Volume & Debit & Kecepatan \\
\cline { 2 - 6 } & $(\mathrm{cm})$ & $\left(\mathrm{cm}^{2}\right)$ & $\left(\mathrm{cm}^{3}\right)$ & $\left(\mathrm{cm}^{3} / \mathrm{s}\right)$ & $(\mathrm{cm} / \mathrm{s})$ \\
\hline 1 & 5 & 1.33 & 2230 & 37.17 & 28.0 \\
\hline 2 & 10 & 1.33 & 2270 & 37.83 & 28.5 \\
\hline 3 & 15 & 1.33 & 2310 & 38.50 & 29.0 \\
\hline 4 & 20 & 1.33 & 2320 & 38.67 & 29.1 \\
\hline 5 & 25 & 1.33 & 2340 & 39.00 & 29.4 \\
\hline
\end{tabular}

Dari hasil perhitungan diperoleh hubungan perubahan kecepatan aliran terhadap kedalaman seperti pada gambar 8 .

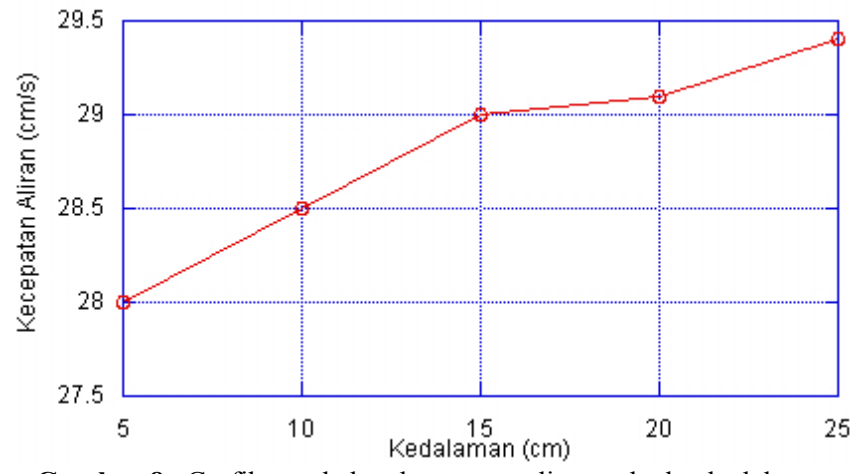

Gambar 8. Grafik perubahan kecepatan aliran terhadap kedalaman

\section{KESIMPULAN}

Kinerja pompa dapat beroperasi dengan mengaktifkan tombol on-off yang berada pada android. Koneksi antara pompa dan smartphone terjadi akibat koneksi arduino uno yang dihubungkan dengan bluethooth. Sinyal bluethooth yang dipeoleh dari alat ditangkap oleh smartphone. Pompa dapat bekerja dengan debit aliran $38.23 \mathrm{~cm}^{3} / \mathrm{s}$ dengan laju aliran sebesar $28.8 \mathrm{~cm} / \mathrm{s}$. 


\section{REFERENSI}

[1] Husodo, B.Y., dan Effendi, R. (2013). Perancangan Sistem Kontrol Dan Pengaman Motor Pompa Air Terhadap Gangguan Tegangan Dan Arus Berbasis Arduino. Jurnal Teknik Elektro, Universitas Mercu Buana. Vol.4 No. 2.

[2] Putra, H.W., Wijono., dan Hasanah, R.N. (2015). Perancangan Sistem Pengendalian Kecepatan Motor Pompa Air Tekanan Konstan. Jurnal mahasiswa TEUB Vol.1 No. 1

[3] Muliawan, A., dan Amalinda, F. (2016). Pengaruh Jumlah Karbon Aktif Pada Filter Air Terhadap Tekanan Keluaran Hasil Filter. Promotif Jurnal kesehatan masyarakat. Vol.5 No.2, Hal 112-120.

[4] Muliawan, A., dan Ilmianih, R. (2016). Metoda Pengurangan Zat Besi Dan Mangan Menggunakan Filter Bertingkat Dengan Penambahan UV Sterilizer Skala Rumah Tangga. Jurnal Ilmiah GIGA Volume 19 (1).

[5] Piyare, R., and Lee, S.R. (2013). Smart Home -Control and Monitoring System Using Smart Phone. Proceedings, The 1st International Conference on Convergence and its Application. ASTL Vol. 24, pp. $83-86$.

[6] Barros, N. Pengendalian Peralatan Elektronik Rumah Tangga Menggunakan Handphone Android Berbasis Microcontroller Arduino. Tugas Akhir.

[7] Turahyo. (2014). Modul pembelajaran Sistem Mikrokontroller,Bontang: Teknik Elektro Sekolah Tinggi Teknologi Bontang. 